\title{
The effect of docosahexaenoic acid and folic acid supplementation on placental apoptosis and proliferation
}

\author{
Mario Klingler ${ }^{1,2}$, Astrid Blaschitz ${ }^{3}$, Christina Campoy ${ }^{4}$, Ana Caño ${ }^{4}$, Anne M Molloy ${ }^{5}$, John M Scott ${ }^{5}$, \\ Gottfried Dohr ${ }^{3}$, Hans Demmelmair ${ }^{1}$, Berthold Koletzko ${ }^{1}$ and Gernot Desoye ${ }^{2 *}$ \\ ${ }^{1}$ Dr von Hauner Children's Hospital, Ludwig-Maximilians-University of Munich, Munich, Germany \\ ${ }^{2}$ Clinic of Obstetrics and Gynaecology, Medical University of Graz, Graz, Austria \\ ${ }^{3}$ Institute of Cell Biology, Histology and Embryology, Medical University of Graz, Graz, Austria \\ ${ }^{4}$ Department of Paediatrics, School of Medicine, University of Granada, Granada, Spain \\ ${ }^{5}$ Department of Clinical Medicine, Trinity College Dublin, Republic of Ireland
}

(Received 13 July 2005 - Revised 21 February 2006 - Accepted 17 March 2006)

\begin{abstract}
The hypothesis was tested that the additional dietary uptake of $n-3$ fatty acids, in particular of DHA and 5-methyltetrahydrofolate (5-MTHF), during the second half of pregnancy would influence proliferation and apoptosis in the full-term human placenta. The diets of pregnant women from Spain ( $n$ 55) were supplemented with modified fish oil and/or 5-MTHF or placebo, and assigned in a random, double-blind manner to one of the four groups. Immunohistochemistry and immunoblotting were used to detect placental proliferation and apoptosis with monoclonal antibodies for key proteins that reflected the extent of both processes: proliferation cell nuclear antigen (PCNA), p53, cytokeratin 18 neoepitope. The PCNA level in the fish oil/5-MTHF-treated group was higher by $66 \%(P<0.05)$ than that of the placebo group, whereas the levels of p53 and cytokeratin 18 neoepitope were unaffected by treatment. PCNA expression was altered only in the trophoblast compartment (placebo 11.1 (SE 0.5) \% v. combination 21.5 (SE 1.2) \%; $P<0.05$ ), whereas the proportion of nuclei stained in endothelial and other stromal cells was similar in the placebo and combined treatment groups. No correlation was found between fish oil or 5-MTHF supplementation and the levels of the proteins. The present data suggest that supplementation with fish oil and/or 5-MTHF had no effect on the parameters reflecting placental proliferation and apoptosis. A defined combination of DHA and 5-MTHF may, however, affect placental proliferation.
\end{abstract}

Apoptosis: Folic acid: $\boldsymbol{n - 3}$ fatty acids: Placenta: Proliferation

The quality of nutrient supply to pregnant women is associated with maternal health and well-being, pregnancy outcome and the rate of complications, and fetal growth (Koletzko et al. 1998). In addition, the intrauterine substrate supply to the growing fetus and the extent and quality of fetal growth have important consequences for its long-term outcome and behavioural and cognitive development, as well as for disease risk in adulthood (von Kries et al. 1999; Waterland \& Garza, 1999; Godfrey \& Barker, 2000; Osmond \& Barker, 2000). With the possible exception of special subgroups, pregnant women in European populations can easily meet their increased energy and protein needs. However, the pregnancy-related increase in reference intakes for a number of micronutrients is far higher than the increase in energy requirement (Elmadfa et al. 2000). Thus, the provision of diets with a high content of selected micronutrients may be of relevance to meet the increased needs for micronutrients.

Of special interest in this regard is the provision of longchain $n$-3 PUFA, such as DHA, and of biologically active folic acid. DHA is an indispensable component of all cell membranes that is incorporated in relatively high concentrations into the brain and other membrane-rich tissues (Gibson et al. 1996). DHA can influence neural maturation and function through the activation of a retinoid $\mathrm{X}$ receptor signalling pathway (de Urquiza et al. 2000).

Supplementation with folic acid or 5-methyltetrahydrofolate (5-MTHF), its most active and abundant form in the tissues, during the early period of pregnancy can reduce the incidence of neural tube defects (Koletzko et al. 1998; Scholl \& Johnson, 2000). It can also contribute to activating the conversion of homocysteine to methionine, and hence to the reduction of plasma concentrations of homocysteine (Jacques et al. 1999). A limitation of intracellular folate may lead to uracil misincorporation into DNA and hence to DNA repair, double-stranded breaks, chromosomal damage and cancer. Although dietary supplementation during pregnancy has recently become popular, the feasibility and efficacy of such preparations need to be determined. Moreover, the safety of supplements must be documented, and any adverse effects on reproductive tissues must be ruled out.

The human placenta separates the maternal and fetal circulation and may protect the fetus from adverse changes in 
the maternal circulation. Its proper functioning is of major importance for nutritional supply to the fetus (Hay, 1994). The morphological architecture and function of the human placenta depends on an adequate balance of proliferation, differentiation and apoptosis. In placentas from early pregnancy, cell proliferation, especially of cytotrophoblasts, is very high, but this diminishes constantly with the duration of pregnancy (Ishihara et al. 2000). In contrast, the rate of apoptosis is low throughout early pregnancy and only increases shortly before delivery (Smith et al. 1997). Maintaining the homeostasis of these basic processes in the placenta is necessary for adequate growth and development of the fetus. An imbalance may result in spontaneous abortion, pre-eclampsia, preterm delivery and reduced fetal growth (Ding et al. 2002; Myatt, 2002; Crocker et al. 2003).

The influence of individual fatty acids, for example EPA and DHA, on apoptosis and proliferation is controversial. In vitro, EPA inhibits cell proliferation, whereas DHA increases apoptosis (Finstad et al. 1998). The influence of DHA and EPA on apoptosis seems to be mediated by different mechanisms (Calviello et al. 1998). The effects of DHA on apoptosis are attributed mainly to its incorporation into the phospholipid bilayer, whereas those of EPA are associated with triacylglycerols of the lipid bodies within the cell. DHA effects on apoptosis are also tissue-dependent. When supplemented with the diet, DHA increases apoptosis in colonic and hepatocarcinoma cells (Calviello et al. 1998; Narayanan et al. 2001), whereas apoptosis is inhibited in neuronal and lymphoma cells (Yano et al. 2000; Akbar \& Kim, 2002).

The effect of folate on the human placenta has been observed only indirectly in an in vitro study. Folate deficiency induces apoptosis in human trophoblasts (Steegers-Theunissen et al. 2000), which would suggest a protective role of folate for the human placenta. However, no direct data are available.

The present study investigated the potential in vivo effect of supplementing the diet of pregnant women with modified fish oil and 5-MTHF on proliferation and apoptosis in the full-term placenta by measuring key proteins of both processes. These include proliferating cell nuclear antigen (PCNA) as marker for proliferation, the product of the tumour suppressor gene p53 as a cellular master switch for both processes, and cytokeratin 18 neoepitope, which is detectable only in apoptotic cells. An enhanced placental proliferation rate in the supplemented groups might be hypothesised as indicative of a prolongation of pregnancy owing to a high intake of fish oil.

\section{Methods}

Subjects and study design

Healthy women between 18 and 40 years of age with an uncomplicated singleton pregnancy were recruited before week 20 of pregnancy in the University Hospital 'San Cecilio' of Granada, Spain. They were then assigned in a random, double-blind manner to one of four groups. Inclusion criteria were no use of fish oil supplements since the beginning of pregnancy and no regular use of folate and vitamin $B_{12}$ supplements after week 16 of gestation. All women habitually consumed an omnivorous diet.

From week 20 of pregnancy onwards, the mothers received daily either: modified fish oil containing $500 \mathrm{mg}$ DHA and
$150 \mathrm{mg}$ EPA (Pronova Biocare, Lysaker, Norway; $n$ 40); $400 \mu \mathrm{g}$ 5-MTHF (delivered as $800 \mu \mathrm{g}$ 6,RS,5-methyltetrahydrofolate; BASF, Ludwigshafen, Germany; $n$ 36), a combination (500 mg DHA, $150 \mathrm{mg}$ EPA, $400 \mu \mathrm{g}$ 5-MTHF; $n$ 37); placebo $(n 41)$ without DHA, EPA or 5-MTHF (Blemil plus; Laboratorios Ordesa, Barcelona, Spain). The components were supplied as $15 \mathrm{~g}$ milk-based portions containing other vitamins and minerals in amounts meeting the estimated additional requirements during the second half of pregnancy (Elmadfa et al. 2000).

The study protocol was approved by the local Ethical Committee. After a detailed explanation of the study, a written consent was obtained from all participating women.

\section{Placental tissue and venous blood collection}

Placental tissue was obtained within 15 min after delivery, thus minimising metabolic changes in the tissue. Because of the heterogeneity of this organ, samples were collected from different locations, including central as well as peripheral locations, following a strict sampling protocol. The amnion and the chorionic plate were excluded. After several washings in $\mathrm{NaCl}\left(0.9 \%, 4^{\circ} \mathrm{C}\right)$ to eliminate blood residues, the tissue pieces were frozen in liquid $\mathrm{N}$ and stored at $-80^{\circ} \mathrm{C}$. For analysis, placental samples from the different locations were pooled as pilot studies showed no influence of sampling site. For immunohistochemistry, placental tissues were fixed in neutral buffered $4 \%$ paraformaldehyde for $12 \mathrm{~h}$, dehydrated and paraffin-embedded. Blood samples were collected from the umbilical cord and maternal peripheral vein and centrifuged at $1500 \mathrm{~g}$ for $5 \mathrm{~min}$. EDTA plasma for folate analysis was stored at $-20^{\circ} \mathrm{C}$ until analysis.

\section{Placental tissue fatty acids and plasma folate}

Fatty acid compositions (\%, w/w) of placental tissue and plasma folate concentrations $(\mathrm{ng} / \mathrm{ml})$ were determined as previously described (Molloy \& Scott, 1997; Klingler et al. 2003).

\section{Tissue culture, western blotting and immunohistochemistry}

Induction of apoptosis. Culture media, fungizone and penicillin/streptomycin were obtained from Invitrogen (Carlsbad, CA, USA), and fetal calf serum was purchased from HyClone (South Logan, UT, USA). To generate a positive control, apoptosis was induced in placental explants by incubation with $1.5 \mathrm{mM}-\mathrm{MgCl}_{2}$ (Black et al. 2001). Briefly, small pieces of villous tissue from the centre of the placental parenchyma were incubated in medium M199 supplemented with $1 \%$ $(\mathrm{v} / \mathrm{v})$ fungizone and $1 \%(\mathrm{v} / \mathrm{v})$ penicillin/streptomycin for $1 \mathrm{~h}$. After two washings in PBS, villi were placed in $1.5 \mathrm{mM}-$ $\mathrm{MgCl}_{2}$ DMEM medium, supplemented with $10 \%$ (v/v) fetal calf serum, $1 \%(\mathrm{v} / \mathrm{v})$ fungizone and $1 \%(\mathrm{v} / \mathrm{v})$ penicillin/streptomycin at $37^{\circ} \mathrm{C}$ under $5 \% \mathrm{CO}_{2}$ for $48 \mathrm{~h}$ (Polliotti et al. 1995).

Protein analysis and quantification using western blotting. All chemicals were obtained from Merck (Darmstadt, Germany) unless stated otherwise. Positive controls were included in all blots. Chemicals for western blotting were obtained from Invitrogen. Chemiluminescence western 
blottings were performed according to the manufacturer's protocol (Invitrogen).

Briefly, approximately $200 \mathrm{mg}$ placental tissue was washed three times in ice-cold PBS and subsequently heated to $95^{\circ} \mathrm{C}$ for $5 \mathrm{~min}$ in lyses buffer containing $0.01 \mathrm{M}$-Tris, $\mathrm{pH} 7.4,1 \%$ SDS (w/v), $1 \mathrm{mm-Na-Orthovanadate} \mathrm{and} \mathrm{complete} \mathrm{protease}$ inhibitor cocktail (Roche, Mannheim, Germany). The mixture was homogenised carefully with a metal-blade homogeniser (IKA, Staufen, Germany), chilled on ice and centrifuged at $1000 \mathrm{~g}$ at $4^{\circ} \mathrm{C}$ for $15 \mathrm{~min}$. The aliquots of supernatant were then transferred into Eppendorf cups. Protein concentration was measured according to the method of Lowry et al. (1951).

Equal amounts of protein from each sample ( $40 \mu \mathrm{g}$ per lane) were separated on 4-12\% Bis-Tris polyacrylamide gradient gels (NuPAGE; Invitrogen) under reducing conditions and transferred to nitrocellulose membranes. Membranes were treated with primary antibodies, as listed in Table 1, and incubated with an alkaline phosphatase-labelled goat-anti-mouse chemiluminescent kit (Western Breeze; Invitrogen) according to the manufacturer's protocol. High-performance chemiluminescence films (Amersham Pharmacia Biotech, Little Chalfont, Buckinghamshire, UK) were used for exposure. Bands corresponding to specific proteins were quantified densitometrically using AlphaEaseFC software, version 3.2.3 (Alpha Innotech Corp., Cannock, UK).

For negative control experiments, the primary antibodies were replaced by isotype-specific mouse $\mathrm{IgG}$ negative control (DAKO, Glostrup, Denmark). The intensity (arbitrary units) of the analysed samples was normalised to a positive control sample that was run on each blot to make interblot comparison possible.

Localisation and semi-quantification by immunohistochemistry. Paraffin sections $(5 \mu \mathrm{m})$ were deparaffinised in xylene and rehydrated in a graded series of alcohol solutions, incubated in $10 \mathrm{mM}$-citrate buffer ( $\mathrm{pH} \mathrm{6.0)} \mathrm{and} \mathrm{boiled} \mathrm{under} \mathrm{pressure} \mathrm{in} \mathrm{an} \mathrm{auto-}$ clave (Decloaking chamber; Biocarta, Hamburg, Germany) at $120^{\circ} \mathrm{C}$ for $3 \mathrm{~min}$. Unspecific protein binding was blocked with activated human serum (20\%), diluted in V-blocking reagent (Lab Vision, Fremont, CA, USA). Primary antibodies (Table 1) were diluted in background reducing agent (DAKO), and their binding was detected by biotinylated goat-anti-mouse antibody and streptavidin-horseradish peroxidase (Lab Vision). After treatment with AEC the sections were slightly counterstained with Mayer's haemalumn and mounted with Kaiser's glycerol gelatine.

The number of stained cells, for example trophoblasts, endothelial and other stromal cells such as blood cells or macrophages, was determined under a light microscope by counting three representative visual fields for each placenta (n 3) per group (original magnification (\% 400). The proportions of labelled nuclei were expressed relative to the total number of cells in the field.

\section{Statistical analysis}

Results are given as means with their standard errors. Group comparisons were carried out using ANOVA and a subsequent post hoc test with Bonferroni's correction. Correlation coefficients were calculated according to Pearson. All statistical tests were performed using SPSS for Windows, release 11.5 (SPSS Inc., Chicago, IL, USA); $P<0.05$ was considered statistically significant.

\section{Results}

\section{Clinical results}

Out of the total of 154 women studied, eight did not finish the clinical trial. Because of logistical restrictions during sample collection, only 100 samples were available for fatty acid analysis. Apoptosis and proliferation were analysed for only sixtysix pieces of placental tissue that could be collected in the strict random sampling mode. Eleven of the samples contained too little protein to allow an analysis of all parameters. The full set of parameters was, therefore, investigated for fiftyfive women. No differences in characteristics of the study population were found between the groups (Table 2).

\section{Fatty acid analyses}

Fatty acid compositions were determined in the placental phospholipid, NEFA and triacylglycerol fractions. The fatty acid patterns of the fifty-five subjects evaluated were representative of the total samples analysed (data not shown). With the exception of the supplemented fatty acids, DHA and EPA, the proportion of all other fatty acids did not differ between the four treatment groups (Fig. 1).

The proportion of DHA in the placental phospholipids was similar in both the fish oil treatment groups (fish oil 5.9 (SE 0.3) $\%$, combined treatment $6.2(\mathrm{SE} 0.3) \%)$, but higher $(P<0.05)$ than in the 'non-fish oil' supplemented groups (placebo 4.8 (SE 0.2) \%, 5-MTHF 4.9 (SE 0.2) \%). Differences $(P<0.05)$ were also measured for EPA (fish oil 0.20 (SE 0.03) \% and combined 0.26 (SE 0.03) \% v placebo 0.11 (SE 0.01) \% and 5-MTHF 0.10 (SE 0.01) \%). In the cytosolic NEFA pool, EPA content differed $(P<0.05)$ between the placebo $(0.4$ (SE $0.1) \%$ ) and combined treatment $(0.6$ (SE 0.1$) \%$ ) groups. Differences in the triacylglycerol fraction were observed for DHA content in the triacylglycerol fraction between the combination (7.9 (SE $0.7 \%)$ and folate-treated (5.2 (SE 0.5) \%) groups, and for EPA content $(P<0.05)$ between the placebo $(0.21$ (SE 0.05) \%) or the 5-MTHF (0.28 (SE 0.07) \%) treated group and the fish oil $(0.56$ (SE 0.12$) \%$ ) or combined (0.43 (SE $0.03) \%$ ) supplemented group. There was no effect on the

Table 1. Primary antibodies used in western blotting and immunohistochemistry

\begin{tabular}{|c|c|c|c|c|c|}
\hline Primary antibody & Clone & Isotype & Dilution western blot & Dilution immunohistochemistry & Source \\
\hline Proliferation cell nuclear antigen & PC10 & Mouse $\lg G_{2 A}$ & $1: 10000$ & $1: 1000$ & $\begin{array}{c}\text { Santa Cruz Biotec, Santa Cruz, } \\
\text { CA, USA }\end{array}$ \\
\hline Cytokeratin 18 neoepitope & M30 & Mouse $\lg G_{2 B}$ & $1: 500$ & $1: 50$ & Roche, Mannheim, Germany \\
\hline
\end{tabular}


Table 2. Characteristics of the study population

(Values are means with their standard errors)

\begin{tabular}{|c|c|c|c|c|c|c|c|c|}
\hline \multirow[b]{3}{*}{ SE } & \multicolumn{8}{|c|}{ Treatment group } \\
\hline & \multicolumn{2}{|c|}{ Placebo (n 12) } & \multicolumn{2}{|c|}{$\begin{array}{l}\text { Fish oil/5-MTHF } \\
(n 11)\end{array}$} & \multicolumn{2}{|c|}{ Fish oil (n 16) } & \multicolumn{2}{|c|}{ 5-MTHF (n 16) } \\
\hline & Mean & SE & Mean & SE & Mean & SE & Mean & SE \\
\hline Length of gestation (d) & 281.5 & $2 \cdot 0$ & $274 \cdot 0$ & 3.9 & $279 \cdot 4$ & $2 \cdot 3$ & $276 \cdot 1$ & $9 \cdot 8$ \\
\hline Maternal age (years) & $31 \cdot 6$ & 0.8 & $30 \cdot 8$ & $1 \cdot 3$ & $28 \cdot 1$ & $1 \cdot 3$ & $29 \cdot 0$ & $1 \cdot 3$ \\
\hline BMI at study entry $\left(\mathrm{kg} / \mathrm{m}^{2}\right)$ & $25 \cdot 2$ & $1 \cdot 1$ & $25 \cdot 8$ & 0.9 & $25 \cdot 2$ & $1 \cdot 1$ & $25 \cdot 1$ & $1 \cdot 0$ \\
\hline BMI at delivery $\left(\mathrm{kg} / \mathrm{m}^{2}\right)$ & $29 \cdot 7$ & 1.5 & $29 \cdot 1$ & $0 \cdot 8$ & $29 \cdot 1$ & 0.5 & $27 \cdot 6$ & $2 \cdot 5$ \\
\hline Placental weight $(\mathrm{g})$ & 586 & 24 & 551 & 52 & 553 & 34 & 527 & 41 \\
\hline Infant's birth weight (g) & 3316 & 71 & 3110 & 191 & 3288 & 127 & 3215 & 129 \\
\hline Infant's birth length $(\mathrm{cm})$ & 51.0 & 0.6 & $49 \cdot 9$ & 0.7 & $50 \cdot 6$ & 0.5 & $50 \cdot 9$ & 0.6 \\
\hline Smoking during pregnancy $(n)$ & 0 & & 3 & & 2 & & 3 & \\
\hline
\end{tabular}

5-MTHF, 5-methyltetrahydrofolate.

For details of subjects and procedures, see p. 183.

DHA

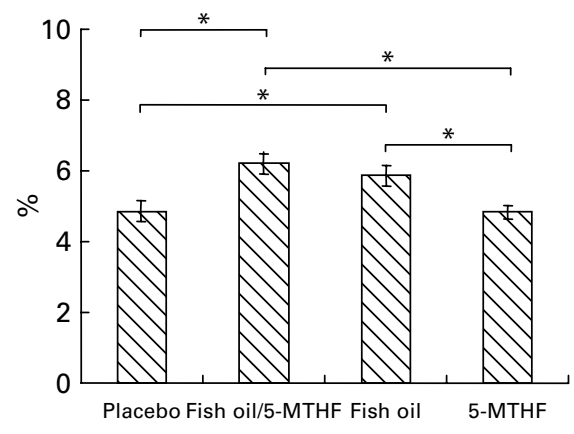

DHA

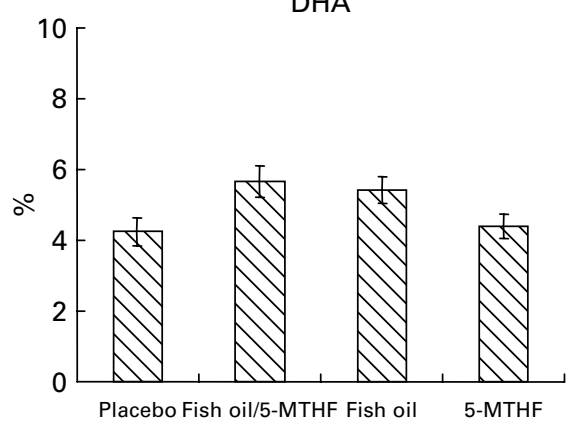

Phospholipids

EPA

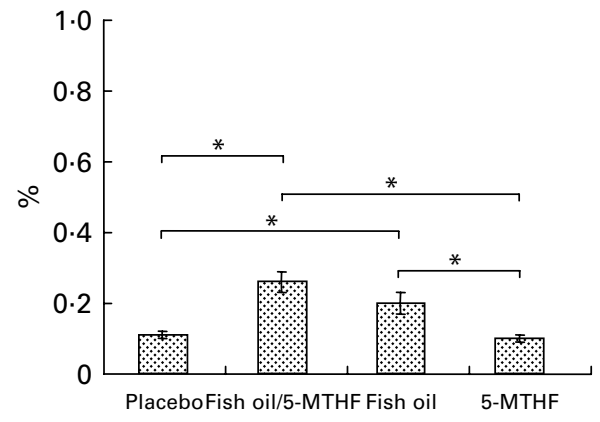

NEFA

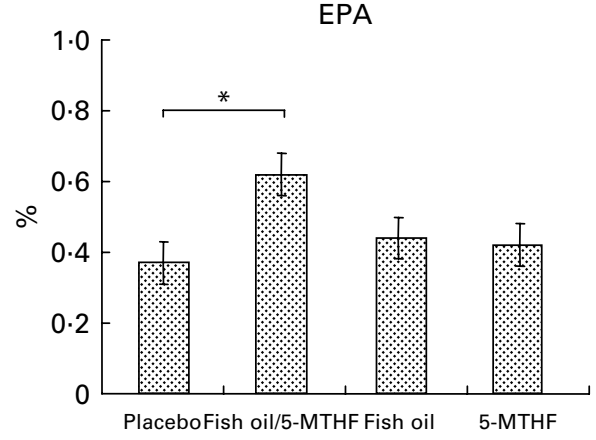

Triacylglycerols

DHA

EPA
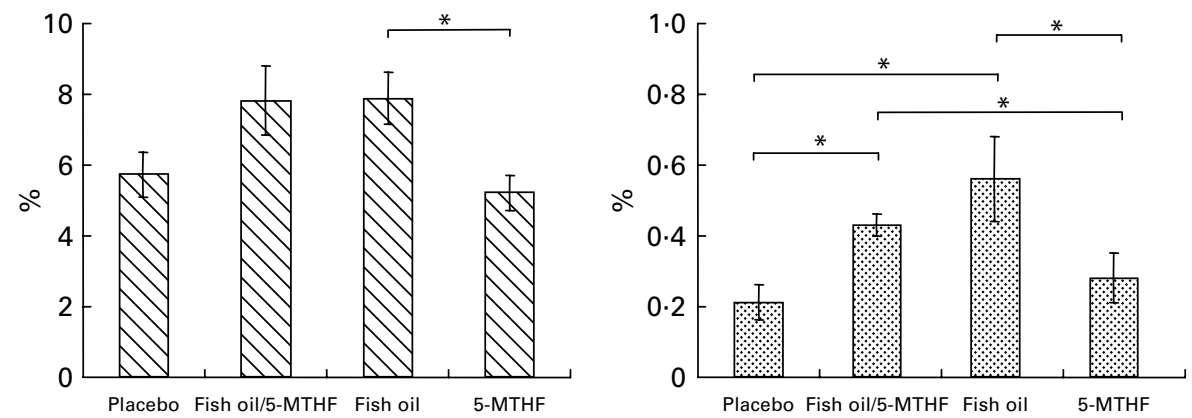

Fig. 1. Proportion of DHA and EPA (\%,w/w) in placental tissue phospholipids, NEFA and triacylglycerols. The groups were supplemented with either placebo ( $n$ 12), modified fish oil and 5-methyltetrahydrofolate (5-MTHF; $n$ 11), modified fish oil ( $n$ 16) or 5-MTHF ( $n$ 16). Mean values were significantly different: ${ }^{*} P<0.05$. For details of subjects and procedures, see p. 183. 
arachidonic content of any of the lipid fractions analysed (Table 3).

\section{Folate concentrations}

A total of 142 samples were analysed for folate concentration. The evaluated subgroup ( $n$ 55) was representative of the total population (data not shown). 5-MTHF intake was reflected in maternal blood plasma concentrations; that is, the 5-MTHF-supplemented groups (5-MTHF 12.6 (SE 1.3 ) $\mathrm{ng} / \mathrm{ml}$, combined 16.0 (SE 1.8 ) ng/ml) had higher levels than the untreated groups (placebo 4.5 (SE 0.8) ng/ml and fish oil 6.6 (SE 1.1) ng/ml; $P<0.05)$. In contrast, no differences were found in fetal plasma (Fig. 2). The fetal:maternal ratio of plasma folate concentration decreased after 5MTHF supplementation (5-MTHF 1.2 (SE 0.1) \% and combined $1.3(\operatorname{SE} 0.1) \% v$. placebo 4.2 (SE 0.9$) \%$ and fish oil 3.0 (SE $0.3 \% ; P<0.05$ ).

\section{Western blotting and immunohistochemistry}

The proliferation marker PCNA, the tumour suppressor protein p53 and the apoptosis marker cytokeratin 18 neoepitope $(42 \mathrm{kDa})$ were quantified to determine proliferation and apoptosis in the term placenta (Figs 3 and 4). The level of PCNA in the fish oil/5-MTHF-treated group was $66 \%$ higher $(P<0.05)$ than that in the placebo group (Fig. 3(A)), whereas levels of p53 and cytokeratin 18 neoepitope were unaffected by treatment (Fig. 3(B), 3(C)). The western blotting results were confirmed by immunohistochemical analysis (Fig. 4).

In order to determine whether the changes in PCNA expression were due to changes in the maternal (trophoblast) or fetal (endothelial cells, other cells) side of the placenta, the proportion of cells immunolabelled for PCNA was further determined for the combined treatment group (Fig. 4(A)) and the placebo group (Fig. 4(B)). The level was higher in the combined treatment group (12.8 (SE 0.6) \% v. 7.3 (SE 0.3) $\% ; P<0.05)$. Clearly, PCNA was altered only in the trophoblast compartment (11.1 (SE 0.5) \% placebo v. 21.5 (SE 1.2) $\%$ combined treatment group; $P<0.05$ ), whereas similar proportions of nuclei were stained in endothelial and other stromal cells (Fig. 5).

The density of p53-labelled nuclei was similar in all four study groups (Fig. 4(C)), which is in agreement with similar

Table 3. Arachidonic acid content in different placental lipid fractions (wt/wt in \%)

(Values are means with their standard errors)

\begin{tabular}{|c|c|c|c|c|c|c|c|c|}
\hline \multirow[b]{3}{*}{ Lipid fraction } & \multicolumn{8}{|c|}{ Supplement } \\
\hline & \multicolumn{2}{|c|}{$\begin{array}{c}\text { Placebo } \\
(n 12)\end{array}$} & \multicolumn{2}{|c|}{$\begin{array}{c}\text { Fish oil/5- } \\
\text { MTHF } \\
(n 11)\end{array}$} & \multicolumn{2}{|c|}{$\begin{array}{l}\text { Fish oil } \\
\quad(n 16)\end{array}$} & \multicolumn{2}{|c|}{$\begin{array}{c}\text { 5-MTHF } \\
(n 16)\end{array}$} \\
\hline & Mean & SE & Mean & SE & Mean & SE & Mean & SE \\
\hline Phospholipids & $21 \cdot 3$ & 0.4 & $21 \cdot 8$ & 0.4 & $21 \cdot 3$ & 0.4 & $22 \cdot 2$ & 0.3 \\
\hline NEFA & $17 \cdot 8$ & 0.8 & $17 \cdot 9$ & 0.5 & 18.5 & 0.5 & $18 \cdot 4$ & 0.6 \\
\hline Triacylglycerols & $12 \cdot 7$ & 0.6 & $12 \cdot 3$ & 0.6 & 12.9 & 0.6 & $12 \cdot 1$ & 0.8 \\
\hline
\end{tabular}

5-MTHF, 5-methyltetrahydrofolate.

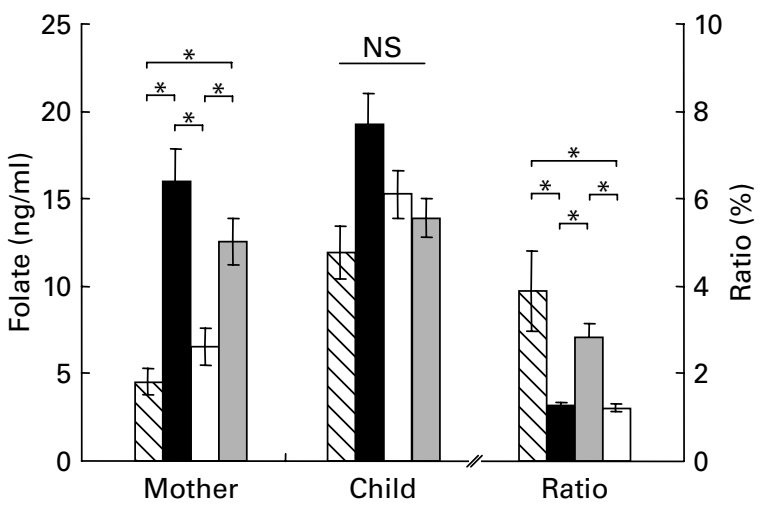

Fig. 2. Effect of 5-methyltetrahydrofolate (5-MTHF) supplementation on fetal and maternal plasma folate concentrations. In maternal plasma, higher concentrations were measured in the folate-supplemented groups. In fetal plasma, no differences were found between the four groups. The ratio of maternal to fetal plasma folate concentration was reduced by additional 5-MTHF uptake. Mean values were significantly different: ${ }^{\star} P<0.05$. $\Delta$, Placebo; $\square$, fish oil/5-MTHF; $\square$, fish oil; $\square, 5-M T H F$. For details of subjects and procedures, see p. 183.

apoptosis rates found by cytokeratin 18 neoepitope staining. In addition, the immunoreactive cells for cytokeratin 18 neoepitope also contained apoptotic bodies, as identified by their characteristic morphology including a round, regular and condensed appearance and dark blue staining. Apoptotic cells were found almost exclusively among extravillous trophoblasts (Fig. 4(D)). These results did not alter when women who smoked were excluded from the analysis.

\section{Discussion}

One of the important questions concerned the potential effect of supplementation with modified fish oil (DHA and EPA) and/or 5-MTHF on the proliferation and apoptosis of different cells in the human placenta. To address this, key proteins of both processes were selected. PCNA is a well-known cell-cycle marker that has, in different studies, been proved as a useful tool for determining the proportion of proliferating cells (Kurki et al. 1988). It was chosen because it can be used in both immunohistochemistry and immunoblotting. PCNA can be immunolocalised mainly in the nuclei of cytotrophoblasts (Ishihara et al. 2000). Although its long half-life of about $20 \mathrm{~h}$ may lead to absolute overestimations (Ishihara et al. 2000), this is unlikely to affect group comparisons.

Protein p53 is a master-switch regulator in the cell, plays an important role as a cell-cycle checkpoint protein and may determine the apoptotic fate of a cell. The p53 protein is localised mainly in nuclei of extravillous trophoblasts, being found in low proportions also in villous cytotrophoblasts and in the syncytiotrophoblast (Haidacher et al. 1995). The PCNA:p53 ratio determines PCNA function. A low ratio leads to DNA repair, whereas DNA replication occurs when the ratio is high (Paunesku et al. 2001).

Apoptotic cells were detected using an antibody (clone M30) for the cytokeratin 18 neoepitope (Austgulen et al. 2002; Huppertz et al. 2003). The detection of cytokeratin 18 neoepitope is more reliable than the conventional terminal deoxynucleotidyl transferase-mediated deoxyuridine 

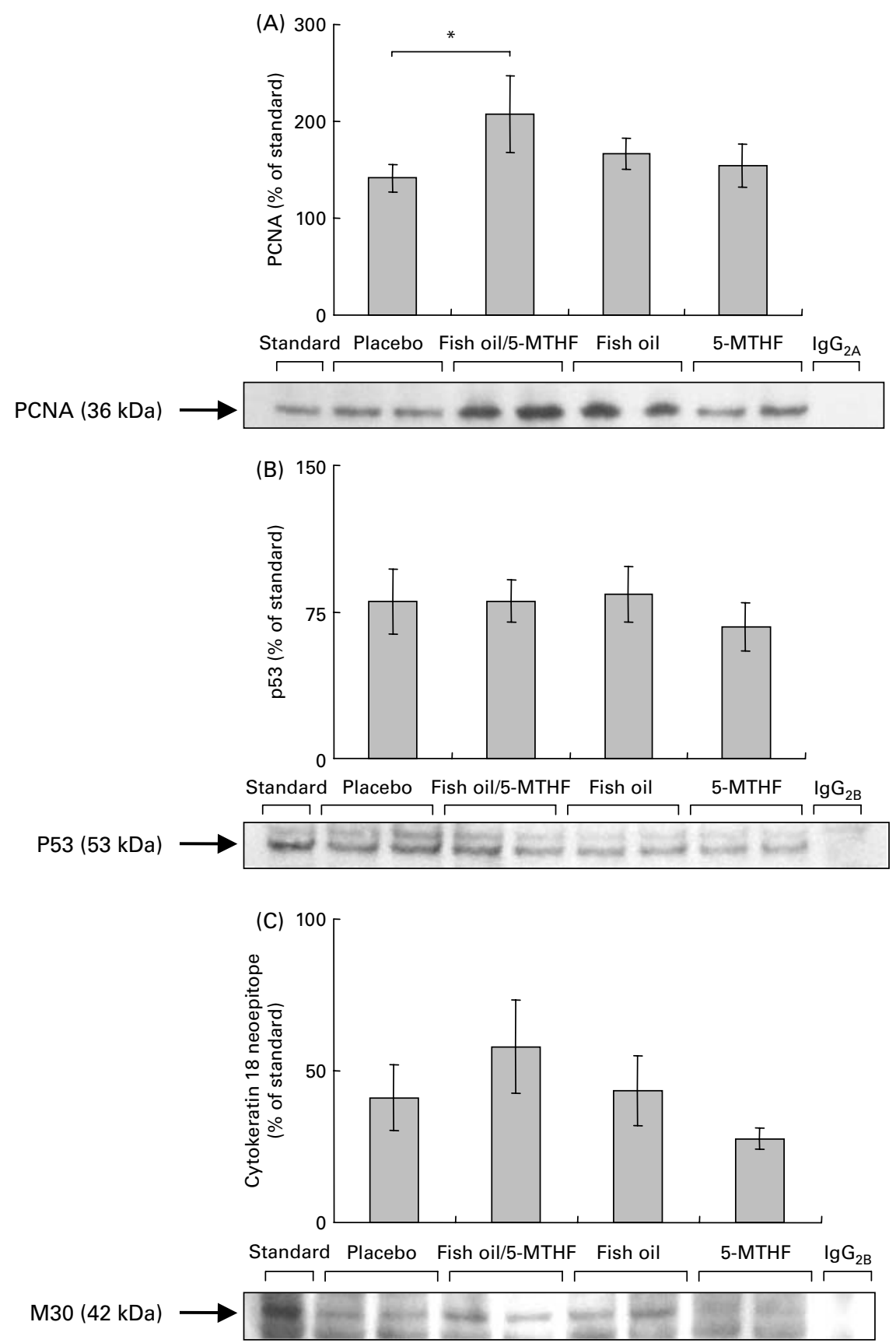

Fig. 3. Immunoblot and densitometric analysis of the proteins of proliferation cell nuclear antigen (PCNA; A), p53 (B) and cytokeratin 18 neoepitope (C) in placental tissue. There were no differences between the study groups except for PCNA in the placebo and the combined modified fish oil/folate-supplemented groups. Data are expressed relative to an internal standard (100\%) run on each gel. 5-MTHF, 5-methyltetrahydrofolate. Mean values were significantly different: ${ }^{\star} P<0.05$. For details of subjects and procedures, see p. 183.

triphosphate nick-end labelling method for monitoring of apoptotic cells in placental tissue (Leers et al. 1999; Austgulen et al. 2002; Huppertz et al. 2003). In addition, the antibody for the neoepitope can be used in both immunohistochemistry and western blotting (Leers et al. 1999), which was another reason for choosing this method.

In some studies, a high intake of fish oil, especially DHA, during pregnancy could lead to prolonged pregnancy and increased birth weight (Olsen et al. 1992; Smuts et al. 2003). We therefore expected an enhanced proliferation rate in the placenta at the end of pregnancy. In the present study, the additional uptake of a modified fish oil (or 5-MTHF) showed no effect on the course or outcome of pregnancy. In keeping with data from others (Montgomery et al. 2003), supplementation with low amounts of DHA during pregnancy does not affect the length of gestation.

The proliferation rate of trophoblastic cells was increased in women who were supplemented with modified fish oil and 5-MTHF in combination, but not in women who were supplemented singly with either fish oil or 5-MTHF. 

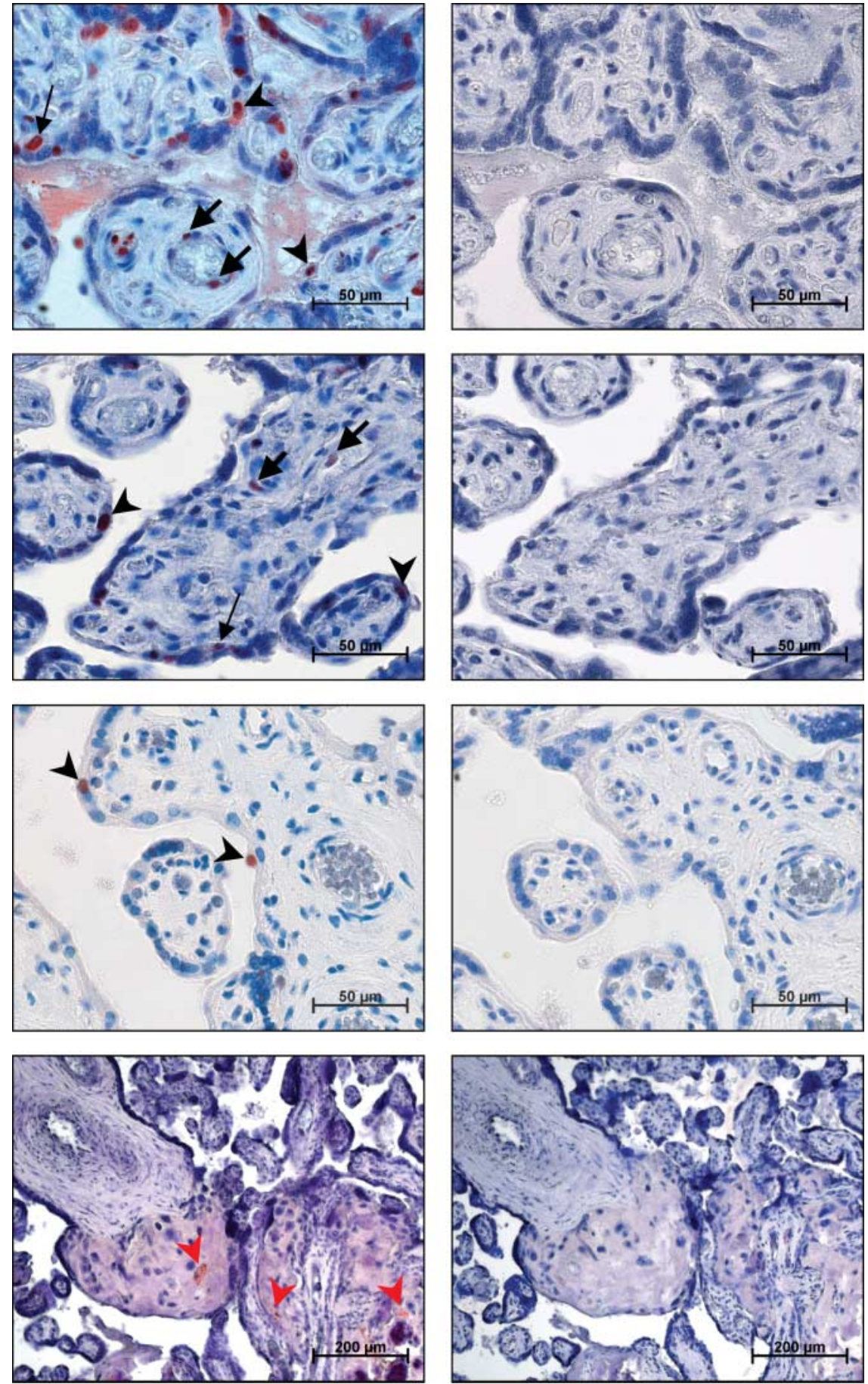

Fig. 4. Immunolocalisation of proliferation cell nuclear antigen (PCNA), cytokeratin 18 neoepitope and p53 in full-term placenta. PCNA immunostaining was stronger in placental tissue from the fish oil/folate-supplemented group (A) than in the placebo group (B). PCNA in endothelium and other cells showed no differences between the two groups. p53 was only rarely detected in all study groups and was found mainly within trophoblasts (C). Cytokeratin 18 neoepitope (D) was rarely labelled in trophoblast cells. $(\mathrm{E}-\mathrm{H}) \mathrm{Ig} \mathrm{G}$ isotype matched negative controls as parallel section. $\boldsymbol{\longrightarrow}$, syncytiotrophoblast; $\longrightarrow$, cytotrophoblast; $\longrightarrow$ thelial and other cells; , apoptotic extravillous trophoblast cells. For details of subjects and procedures, see p. 183.

The enhanced proliferation was found only in villous cytotrophoblasts, whereas endothelial and other stromal cells were not affected. These findings are notable because, in fish-oil supplementation studies, enhanced DHA contents have been measured in the fetal circulation (van Houwelingen et al. 1995). Thus, if the effect depended on the additional intake of DHA, proliferation rates would also be higher in endothelial and other stromal cells. One potential confounder is smoking during pregnancy, which can affect the level of PCNA in the placental trophoblasts (Gruslin et al. 2001). In the present study, however, there was no difference in the proportion of smokers in the four groups $(X 2=0.680)$, and the exclusion of women who smoked did not change the results. Therefore, the exclusive upregulation of PCNA production 


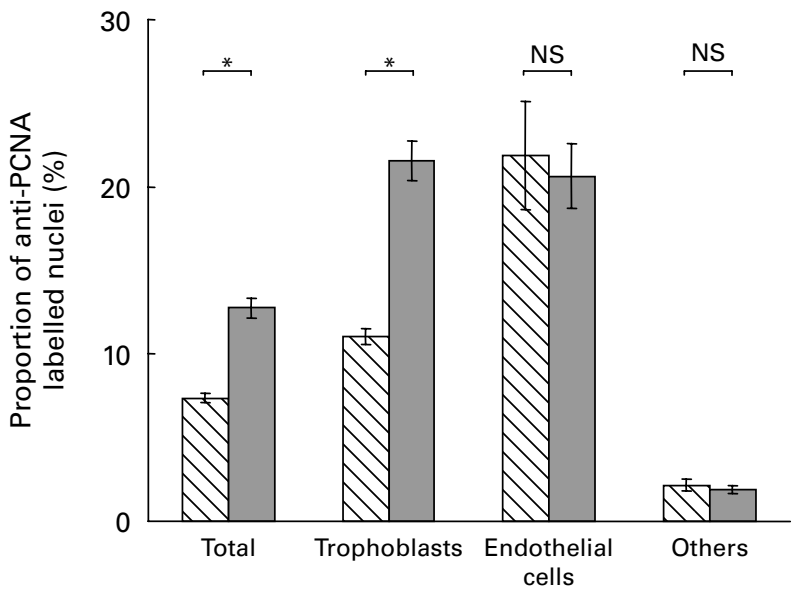

Fig. 5. A higher proportion of nuclei were immunolabelled in the fish oil/folate group $(Z ; n 3)$ than the placebo group $(\square ; n 3)$, because of an exclusive increase in the trophoblast compartment. The labelling of endothelial cells and other cells, such as fibroblasts, blood cells and macrophages, remained unchanged. PCNA, proliferation cell nuclear antigen. Mean values were significanlty different: ${ }^{*} P<0.05$. For details of subjects and procedures, see $p .183$.

in the trophoblast probably reflects a differential susceptibility of the cells to changes in ambient DHA level.

The specific mechanism(s) accounting for the effects of DHA and 5-MTHF in combination compared with DHA alone are unknown. 5-MTHF may have sensitised the trophoblast for a DHA effect or vice versa, or both nutrients may have to cooperate to achieve the effect; thus, the effect would be absent with an elevated concentration of only one of the nutrients because of limited availability of the other. The nutrients may alter nutritionally sensitive hormones in the mother that will then lead to the changes in the placenta, or they may have a direct effect on trophoblast cell-cycle regulation. In addition, local factors derived from the nutrients may directly or indirectly stimulate trophoblast proliferation. Further in vivo and in vitro studies are needed and are ongoing in our laboratory.

The consequence of increased trophoblast proliferation as a result of the dietary intervention is unknown. It is usually found in placentas when mothers are anaemic (Kosanke et al. 1998), diabetic (Desoye \& Kaufmann, 2005) or in pre-eclampsia (Arnholdt et al. 1991). However, unlike the results in the present study, pre-eclampsia is also associated with increased apoptosis of the trophoblast, i.e. trophoblast turnover. Large nutritional intervention studies will be needed to decide whether the diet-induced placental changes have a protective or promoting effect for the development of severe pathologies of pregnancy such as pre-eclampsia and intrauterine growth retardation.

The higher DHA contents measured in membrane phospholipids as well as the slightly enhanced DHA proportions in cytosolic triacylglycerols and NEFA had no effect on apoptosis in full-term placentas. The uptake of high EPA concentrations decreases the arachidonic acid content of plasma phospholipids and triacylglycerols (van Houwelingen et al. 1995; Helland et al. 2001; Rodriguez et al. 2003). The increase in arachidonic acid NEFA or altered arachidonic acid levels in membrane phospholipids may induce apoptosis in different cell types (Rudolph et al. 2001). In the present study, we did not observe any effect of EPA on the arachidonic acid content of any of the placental lipid fractions analysed. The absence of such a change might also be an explanation for the lack of effect on placental apoptosis.

In summary, maternal supplementation with fish oil enhanced the DHA and EPA contents of placental membrane phospholipids. When pregnant women were supplemented singly either with modified fish oil or 5-MTHF, the proliferation did not change compared with placebo. In the group receiving both supplements, however, an enhanced proliferation rate was shown in the trophoblast compartment but not in endothelial or other stromal cells. In contrast, the degree of apoptosis was unaltered in all treatment groups. The present data suggest that the combination of folic acid and DHA could alter placental proliferation in the full-term placenta, but the detailed mechanisms have to be elucidated.

\section{Acknowledgements}

We are grateful for the support of the mothers participating and the staff of the Department of Paediatrics of the University of Granada, Spain. The studies were carried out with partial financial support from the Commission of the European Communities, specific RTD programme 'Quality of Life and Management of Living Resources', within the 5 Framework Program 'Research grant Nutrition and Healthy Lifestyle', grant number CLK1-CT-1999-00 888. It does not necessarily reflect the views of the Commission and in no way anticipates future policy in this area. M.K. was supported financially in part by the Child Health Foundation, Munich, Germany and Danone, Institut für Ernährung, Munich, Germany. G. D. was supported in part by grant 10053 , Jubilee Fund, Austrian National Bank, Vienna, Austria.

\section{References}

Akbar M \& Kim HY (2002) Protective effects of docosahexaenoic acid in staurosporine-induced apoptosis: involvement of phosphatidylinositol-3 kinase pathway. J Neurochem 82, 655-665.

Arnholdt H, Meisel F, Fandrey K \& Lohrs U (1991) Proliferation of villous trophoblast of the human placenta in normal and abnormal pregnancies. Virchows Arch B Cell Pathol Incl Mol Pathol 60, 365-372.

Austgulen R, Chedwick L, Isaksen CV, Vatten L \& Craven C (2002) Trophoblast apoptosis in human placenta at term as detected by expression of a cytokeratin 18 degradation product of caspase. Arch Pathol Lab Med 126, 1480-1486.

Black S, Yu H, Lee J, Sachchithananthan M \& Medcalf RL (2001) Physiologic concentrations of magnesium and placental apoptosis: prevention by antioxidants. Obstet Gynecol 98, 319-324.

Calviello G, Palozza P, Piccioni E, Maggiano N, Frattucci A, Franceschelli P \& Bartoli GM (1998) Dietary supplementation with eicosapentaenoic and docosahexaenoic acid inhibits growth of Morris hepatocarcinoma 3924A in rats: effects on proliferation and apoptosis. Int J Cancer 75, 699-705.

Crocker IP, Cooper S, Ong SC \& Baker PN (2003) Differences in apoptotic susceptibility of cytotrophoblasts and syncytiotrophoblasts in normal pregnancy to those complicated with preeclampsia and intrauterine growth restriction. Am J Pathol 162, 637-643.

Desoye G \& Kaufmann P (2005) The human placenta in diabetes. In Diabetology of Pregnancy, pp. 94-109 [J Djelmis, G Desoye and M Ivanisevic, editors] Basel: Karger.

de Urquiza AM, Liu S, Sjoberg M, Zetterstrom RH, Griffiths W, Sjovall J \& Perlmann T (2000) Docosahexaenoic acid, a ligand for the retinoid X receptor in mouse brain. Science 290, 2140-2144. 
Ding F, Fu GQ, Xing FQ, Chen SL \& Liu YX (2002) Effect of abnormal apoptosis in human decidual tissue during early gestation on pregnancy. Di Yi Jun Yi Da Xиe Xие Bao (Academic Journal of The First Medical College of PLA) 22, 145-147.

Elmadfa I, Erbersdobler H, Gassmann B, Stehle P, Walter P \& Wolfram G (2000) Referenzwerte für die Nährstoffzufuhr (Reference Values for Nutrient Intake) [Deutsche Gesellschaft für Ernährung, Östereichische Gesellschaft für Ernährung, Schweizerische Gesellschaft für Ernährungsforschung and Schweizerische Vereinigung für Ernährung, editors]. Frankfurt am Main: Unschau Braus.

Finstad HS, Drevon CA, Kulseth MA, Synstad AV, Knudsen E \& Kolset SO (1998) Cell proliferation, apoptosis and accumulation of lipid droplets in U937-1 cells incubated with eicosapentaenoic acid. Biochem J 336, 451-459.

Gibson RA, Neumann MA \& Makrides M (1996) Effect of dietary docosahexaenoic acid on brain composition and neural function in term infants. Lipids 31, S177-S181.

Godfrey KM \& Barker DJ (2000) Fetal nutrition and adult disease. Am J Clin Nutr 71, 1344S-1352S.

Gruslin A, Qiu Q \& Tsang BK (2001) Influence of maternal smoking on trophoblast apoptosis throughout development: possible involvement of Xiap regulation. Biol Reprod 65, 1164-1169.

Haidacher S, Blaschitz A, Desoye G \& Dohr G (1995) Immunohistochemical evidence of p53 protein in human placenta and choriocarcinoma cell lines. Hum Reprod 10, 983-988.

Hay WW Jr (1994) Placental transport of nutrients to the fetus. Horm Res 42, 215-222.

Helland IB, Saugstad OD, Smith L, Saarem K, Solvoll K, Ganes T \& Drevon CA (2001) Similar effects on infants of n-3 and n-6 fatty acids supplementation to pregnant and lactating women. Pediatrics 108, E82.

Huppertz B, Kingdom J, Caniggia I, Desoye G, Black S, Korr H \& Kaufmann P (2003) Hypoxia favours necrotic versus apoptotic shedding of placental syncytiotrophoblast into the maternal circulation. Placenta 24, 181-190.

Ishihara N, Matsuo H, Murakoshi H, Laoag-Fernandez J, Samoto T \& Maruo T (2000) Changes in proliferative potential, apoptosis and Bcl-2 protein expression in cytotrophoblasts and syncytiotrophoblast in human placenta over the course of pregnancy. Endocr $J$ 47, 317-327.

Jacques PF, Selhub J, Bostom AG, Wilson PW \& Rosenberg IH (1999) The effect of folic acid fortification on plasma folate and total homocysteine concentrations. N Engl J Med 340, 1449-1454.

Klingler M, Demmelmair H, Larque E \& Koletzko B (2003) Analysis of FA contents in individual lipid fractions from human placental tissue. Lipids 38, 561-566.

Koletzko B, Aggett PJ, Bindels JG, Bung P, Ferre P, Gil A, Lentze MJ, Roberfroid M \& Strobel S (1998) Growth, development and differentiation: a functional food science approach. Br J Nutr 80, Suppl. 1, S5-S45.

Kosanke G, Kadyrov M, Korr H \& Kaufmann P (1998) Maternal anemia results in increased proliferation in human placental villi. Trophoblast Res 11, 339-357.

Kurki P, Ogata K \& Tan EM (1988) Monoclonal antibodies to proliferating cell nuclear antigen (PCNA)/cyclin as probes for proliferating cells by immunofluorescence microscopy and flow cytometry. J Immunol Methods 109, 49-59.

Leers MPG, Kolgen W, Bjorklund V, Bergman T, Tribbick G, Persson B, Bjorklund P, Ramaekers FCS, Bjorklund B \& Nap M (1999) Immunocytochemical detection and mapping of a cytokeratin 18 neo-epitope exposed during early apoptosis. $J$ Pathol 187, $567-572$.
Lowry O, Rosebrough N, Farr A \& Randall R (1951) Protein measurement with Folin-phenol reagent. J Biol Chem 193, 265-275.

Molloy AM \& Scott JM (1997) Microbiological assay for serum, plasma, and red blood cell folate using cryopreserved, microtiter plate method. Meth Enzymol 281, 43-45.

Montgomery C, Speake BK, Cameron A, Sattar N \& Weaver LT (2003) Maternal docosahexaenoic acid supplementation and fetal accretion. Br J Nutr 90, 135-145.

Myatt L (2002) Role of placenta in preeclampsia. Endocrine 19, $103-111$.

Narayanan BA, Narayanan NK \& Reddy BS (2001) Docosahexaenoic acid regulated genes and transcription factors inducing apoptosis in human colon cancer cells. Int J Oncol 19, 1255-1262.

Olsen SF, Sorensen JD, Secher NJ, Hedegaard M, Henriksen TB, Hansen HS \& Grant A (1992) Randomised controlled trial of effect of fish-oil supplementation on pregnancy duration. Lancet 339, 1003-1007.

Osmond C \& Barker DJ (2000) Fetal, infant, and childhood growth are predictors of coronary heart disease, diabetes, and hypertension in adult men and women. Environ Health Perspect 108, Suppl. 3, $545-553$.

Paunesku T, Mittal S, Proticacute M, Oryhon J, Korolev SV, Joachimiak A \& Woloschak GE (2001) Proliferating cell nuclear antigen (PCNA): ringmaster of the genome. Int J Radiat Biol 77, $1007-1021$

Polliotti BM, Abramowsky C, Schwartz DA, Keesling SS, Lee GR, Caba J, Zhang W, Panigel M \& Nahmias AJ (1995) Culture of first-trimester and full-term human chorionic villus explants: role of human chorionic gonadotropin and human placental lactogen as a viability index. Early Pregnancy 1, 270-280.

Rodriguez A, Raederstorff D, Sarda P, Lauret C, Mendy F \& Descomps B (2003) Preterm infant formula supplementation with $\alpha$-linolenic acid and docosahexaenoic acid. Eur J Clin Nutr 57, 727-734.

Rudolph IL, Kelley DS, Klasing KC \& Erickson KL (2001) Regulation of cellular differentiation and apoptosis by fatty acids and their metabolites. Nutr Res 21, 381-393.

Scholl TO \& Johnson WG (2000) Folic acid: influence on the outcome of pregnancy. Am J Clin Nutr 1295S-1303S.

Smith SC, Baker PN \& Symonds EM (1997) Placental apoptosis in normal human pregnancy. Am J Obstet Gynecol 177, 57-65.

Smuts CM, Huang M, Mundy D, Plasse T, Major S \& Carlson SE (2003) A randomized trial of docosahexaenoic acid supplementation during the third trimester of pregnancy. Obstet Gynecol 101, 469-479.

Steegers-Theunissen RP, Smith SC, Steegers EA, Guilbert LJ \& Baker PN (2000) Folate affects apoptosis in human trophoblastic cells. Br J Obstet Gynaecol 107, 1513-1515.

van Houwelingen AC, Sorensen JD, Hornstra G, Simonis MM, Boris J, Olsen SF \& Secher NJ (1995) Essential fatty acid status in neonates after fish-oil supplementation during late pregnancy. $\mathrm{Br} \mathrm{J}$ Nutr 74, 723-731.

von Kries R, Koletzko B, Sauerwald T, von Mutius E, Barnert D, Grunert V \& von Voss H (1999) Breast feeding and obesity: cross sectional study. Br Med J 319, 147-150.

Waterland RA \& Garza C (1999) Potential mechanisms of metabolic imprinting that lead to chronic disease. Am J Clin Nutr 69, 179-197.

Yano M, Kishida E, Iwasaki M, Kojo S \& Masuzawa Y (2000) Docosahexaenoic acid and vitamin $\mathrm{E}$ can reduce human monocytic U937 cell apoptosis induced by tumor necrosis factor. $J$ Nutr 130, 1095-1101. 